\title{
Erratum to: Shock Wave-Induced Damage and Poration in Eukaryotic Cell Membranes
}

\author{
Luz M. López-Marín ${ }^{1}$ Blanca E. Millán-Chiu ${ }^{2} \cdot K^{1}$ aren Castaño-González ${ }^{1}$ • \\ Carmen Aceves $^{3} \cdot$ Francisco Fernández $^{1}$ - Alfredo Varela-Echavarría ${ }^{3}$. \\ Achim M. Loske ${ }^{1}$
}

Published online: 7 September 2016

(c) Springer Science+Business Media New York 2016

\section{Erratum to: J Membrane Biol \\ DOI 10.1007/s00232-016-9921-2}

The original version of this article unfortunately contained a mistake. The lable in Fig. $4 a, b$ was incorrect in the published version of the article. The scale bar has the label "50 microseconds" instead of "50 micrometers". The corrected Fig. 4 is given below.

The online version of the original article can be found under doi:10.1007/s00232-016-9921-2.

Achim M. Loske

loske@fata.unam.mx

1 Centro de Física Aplicada y Tecnología Avanzada,

Universidad Nacional Autónoma de México, Boulevard

Juriquilla 3001, 76230 Querétaro, Qro., Mexico

2 CONACYT - Centro de Física Aplicada y Tecnología Avanzada, Universidad Nacional Autónoma de México, Boulevard Juriquilla 3001, 76230 Querétaro, Qro., Mexico

3 Instituto de Neurobiología, Universidad Nacional Autónoma de México, Boulevard Juriquilla 3001, 76230 Querétaro, Qro., Mexico 
(a)

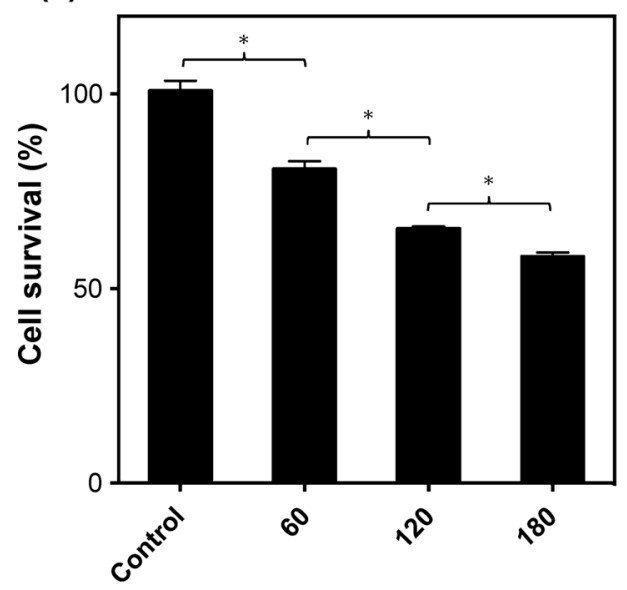

Number of shock waves

Fig. 4 Cell membrane survival, permeability, and resealing of shock wave exposed HEK-293 cells. Underwater shock wave treatments induced a dose-dependent decrease in cell survival (a). Trypan blue is internalized into cells exposed to 120 shock waves (b) but is excluded (c)

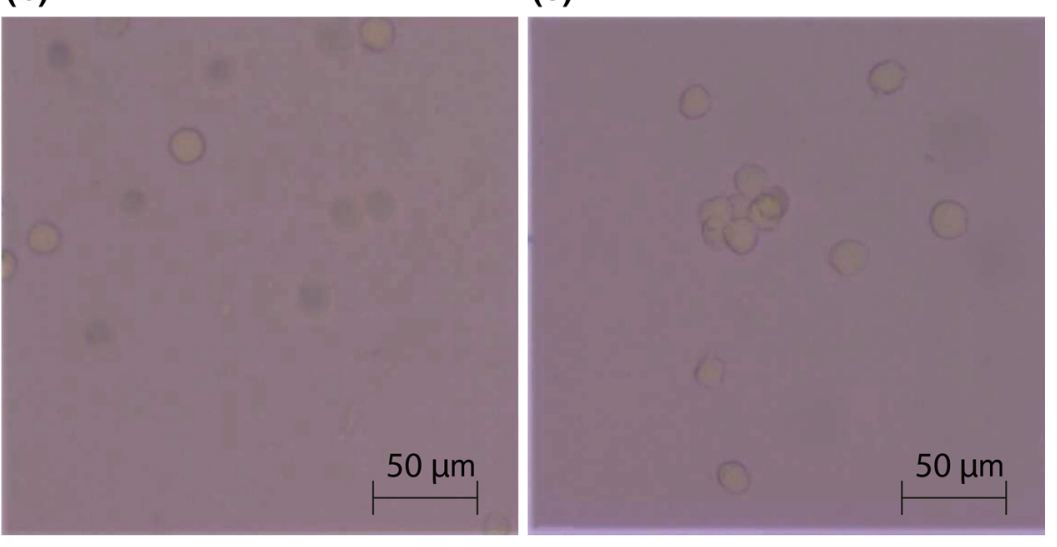

from cells $15 \mathrm{~s}$ after shock wave exposure (c). Bars represent mean $\pm \mathrm{SD}(n=3)$. ${ }^{*} P \leq 0.05$. Images correspond to hemocytometer small square samples (containing $6.25 \times 10^{-3} \mu \mathrm{l}$ of cell suspension) 